\title{
Social representations of mothers about gestational hypertension and premature birth ${ }^{1}$
}

\author{
Nilba Lima de Souza ${ }^{2}$ \\ Ana Cristina Pinheiro Fernandes de Araújo ${ }^{3}$ \\ Iris do Ceu Clara Costa ${ }^{3}$
}

Objective: To identify the meanings attributed by mothers to hypertensive disorders of pregnancy (HDPs) and their consequences, such as premature birth and hospitalization of the infant in the neonatal intensive care unit (NICU). Method: A qualitative study, based on the Central Nucleus Theory, with 70 women who had hypertensive disorders of pregnancy and preterm delivery. We used the technique of free word association (FWAT) with three stimuli: high blood pressure during pregnancy, prematurity and NICU. Results: We obtained 1007 evocations, distributed as follows: high blood pressure during pregnancy (335) prematurity (333) and NICU (339). These constituted three thematic units: representation of HDPs, prematurity and the NICU. The categories death and negative aspects were inherent to the three units analyzed, followed by coping strategies and needs for care present in HDPs and prematurity. Conclusion: The study had death as its central nucleus, and highlighted the subjective aspects present in the high risk pregnancy and postpartum cycle. It is hoped that this research will contribute to qualifying nursing care for women confronting the problem of HDPs, so that they can cope with less impacts from the adverse effects of high risk pregnancy and birth.

Descriptors: Pregnancy, High-Risk; Pre-Eclampsia; Obstetrical Nursing; Infant, Premature.

\footnotetext{
${ }_{1}$ Paper extracted from doctoral dissertation "Significados e percepções de puérperas sobre as síndromes hipertensivas da gravidez e parto prematuro", presented to Universidade Federal do Rio Grande do Norte, Natal, RN, Brazil.

2 PhD, Professor, Departamento de Enfermagem, Universidade Federal do Rio Grande do Norte, Natal, RN, Brazil.

${ }^{3} \mathrm{PhD}$, Associate Professor, Centro de Biociências, Universidade Federal do Rio Grande do Norte, Natal, RN, Brazil.
}

Corresponding Author:

Nilba Lima de Souza

Universidade Federal do Rio Grande do Norte. Centro de Ciências da Saúde

Av. Senador Salgado Filho, 3000

Bairro: Lagoa Nova

CEP: 59078-900, Natal, RN, Brasil

E-mail: nilbalima@ufrnet.br 


\section{Introduction}

Hypertension induced by the pregnancy status, known as hypertensive disorders of pregnancy (HDPs), is conceptualized as the increase in arterial pressure that is manifested, more specifically, in the second half of pregnancy ${ }^{(1)}$. These syndromes impact between $10 \%$ to $22 \%$ of the pregnancies considered high risk, and are among the diseases with the greatest impact, complications of pregnancy and childbirth, with a tendency for premature births ${ }^{(1-2)}$. In developed countries, $16.1 \%$ of all maternal deaths are caused by HDPs and hemorrhage ${ }^{(3)}$. In Brazil, data demonstrate that of the HDPs, pre-eclampsia is the most frequent complication during pregnancy and childbirth, around $5-10 \%$ of pregnancies, and that it is the leading cause of maternal and fetal death ${ }^{(4)}$

High levels of maternal arterial pressure are associated with impaired fetal growth during the third trimester of pregnancy and increase the risk of adverse outcomes such as preterm birth and perinatal death $^{(5)}$. Studies reveal that $11 \%$ of births between the 34th and 37th weeks of pregnancy are women who developed preeclampsia; and, in the case of recurrence, it is doubled to $22 \%{ }^{(6-7)}$. They also indicate that $33 \%$ of premature births arising from pregnancy with preeclampsia required intensive $\operatorname{care}^{(7)}$. In this way, it is clear that the HDPs favor premature birth and subsequent hospitalization in a neonatal intensive care unit (NICU), and are considered, therefore, to be a high risk pregnancy and perinatal condition.

It is worth highlighting the emotional issues that surround motherhood in a situation of high risk pregnancy. There are reports in the literature of subjective aspects present in pregnancy that lead to arterial hypertension, revealing anxieties and insecurity in women who experience threats of maternal and fetal death $^{(8)}$.

However, in the presence of a high risk pregnancy and when the outcome of childbirth occurs earlier than planned, the mother deconstructs the ideal of motherhood and moves into living with the reality of a child that inspires care and risk of death. This understanding leads to presuppose that a pregnancy with hypertensive syndrome and, as a consequence, the birth of a premature child requiring hospitalization in the NICU, can induce women to experience feelings of a diverse nature, which constitute the meanings for her motherhood in a high risk situation. We recognized the need to investigate these subjective aspects present in the experience of a pregnancy that ends with the premature birth of a child, based on the following research question: What are the social representations of mothers about the HDP sequence leading to premature birth, which evolved into the hospitalization of a child in the NICU?

From this perspective, the study aimed to identify the significance attributed by pregnant mothers to hypertensive disorders of pregnancy, and their consequences, such as premature birth and hospitalization of the child in the NICU.

\section{Method}

An exploratory, descriptive and qualitative study, based on the theory of social representations based on the Central Nucleus Theory(9). Data collection occurred in 2009, and a university maternity hospital, a reference organization in the state of Rio Grande do Norte (RN), Brazil, for high risk pregnancy, labor, birth and postpartum, was used as the research site.

The study included 70 women with HDPs, 48 hours or more after the occurrence of preterm birth, who had completed at least two NICU visits to their child. The convenience sample was defined by the saturation criterion of repetition of terms, according to the methodology used. The project was approved by the Committee on Ethics in Research of the Universidade Federal do Rio Grande do Norte (CEP-UFRN), under No. 195/06. The Terms of Free and Informed Consent was read and signed by all participants.

Data were collected from May to October of 2009, in the inpatient maternity unit, using a questionnaire to collect sociodemographic and obstetrical data from participants, and another designed for using the free word association technique (FWAT).

The FWAT is a projective technique used as a strategy to access the central nucleus of social representations, in which free verbal or nonverbal evocations are suggested, by means of inducing stimuli that are coherent with the research objectives ${ }^{(9-10)}$. We opted for verbal constructions and the following stimuli: HDP was replaced by the term "high pressure in pregnancy", considering it closer to the 
level of understanding of the interviewees; prematurity and NICU. Five evocations considered by the women to be the most important, and justification, were requested for each of these words.

The evocations obtained through FWAT were coded, following these steps: typing the evoked words inherent to each inducing stimulus; preparation of dictionaries, considering not only adjectives, but similar expressions; and finally, construction of a database in an electronic spreadsheet.

Subsequently the material was subjected to lexicographical analysis conducted by the EVOC (Ensemble L'Analyse des Programmes Permettant evocations) software, 2000 version, which organizes the words evoked in order of frequency and mean number of evocations(11), distributing them into four quadrants, also called four model cases, or a scatter plot. It confers different degrees of centrality to the vocabulary, each quadrant constituting a nucleus of representation ${ }^{(11-12)}$, as shown in Figure 1.

The vertical axis refers to the mean order of evocation (MOE). The elements with less MOE were in the lower left quadrant and those which possessed greater MOE were on the right. On the horizontal axis, the frequencies ( $f$ ) of invocations are found, as follows: in the upper quadrants, the higher frequencies; and, in lower quadrants, the lowest frequencies. In the upper left, quadrant 1 , the elements evoked with lower order of evocation are considered the elements of the central nucleus of social representation, because they represent a collective idea. In the lower right, quadrant 3, the lower frequencies of evocation and higher MOEs are found, integrated into the peripheral nucleus. They constitute individualized representations that provide sustainability to the central nucleus ${ }^{(9)}$.

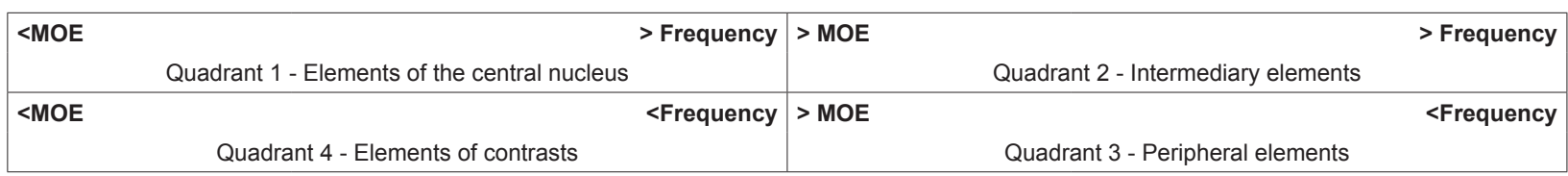

Figure 1 - Table of four model cases standardized by Vergès $(1992)^{(11)}$

For purposes of analysis, the other nuclei were not considered important in the social representation, but, more recently, studies have shown that by its proximity with the central nucleus, the second quadrant composed of intermediate elements exerts influences on the representative system, by having very close values of the elements that compose the central system of representation ${ }^{(9)}$. This fact was observed in this study and, therefore, it was decided to consider them as representative of the object studied.

\section{Results}

\section{Characterization of the women}

There was a mean age of 28 years, with a predominance of middle school education (58.60\%), a household income of up to three minimum wages $(75.70 \%)$, a mean number of four prenatal visits, a predominance of Cesarean birth (90\%), and the majority were primiparous $(57.14 \%)$. Low birth weight $(<1500$ g) was recorded in $42.90 \%$ of the newborns.

The FWAT consisted of a total of 1007 evocations, distributed as follows: for the stimulus, high blood pressure in pregnancy, 335 words were evoked; for prematurity, 333 words; and, for NICU, 339 expressions. These are presented below in three thematic units and their respective categories, with explanations from the women about the significance of some of these evocations.

\section{Significance attributed to hypertensive disorders of pregnancy}

With respect to the inducing stimulus, high pressure in pregnancy, $91.3 \%$ of the words evoked were of a similar nature, which reflected the homogeneity in the responses of the women. They were divided into five categories, as shown in Figure 2. 


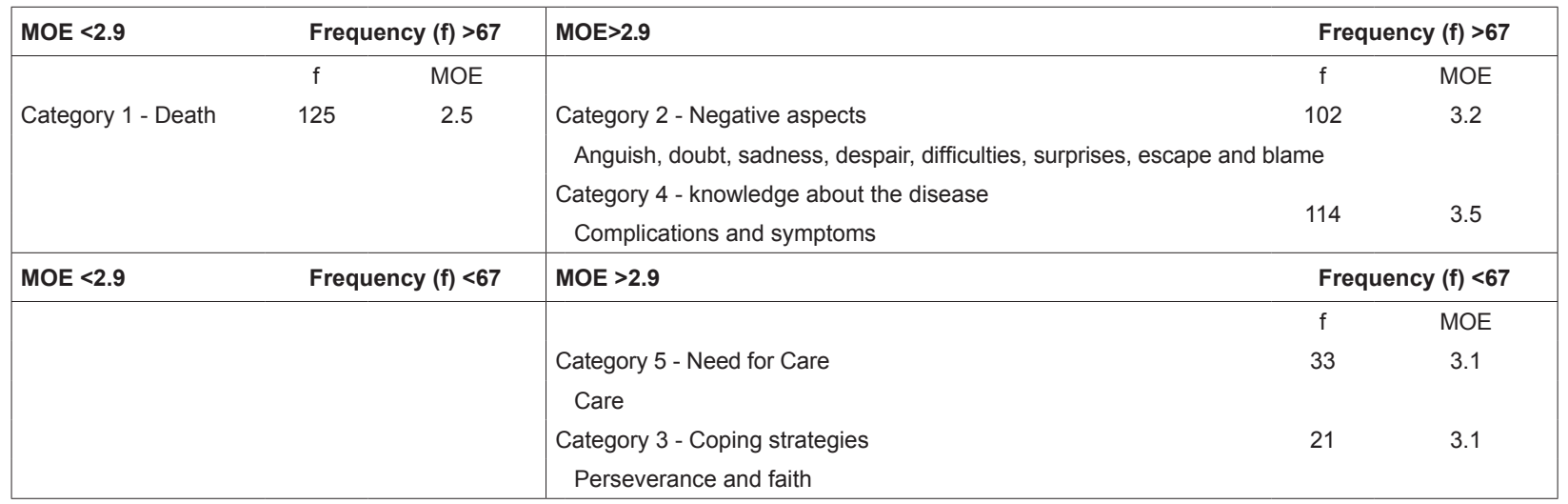

Figure 2 - Identification of the structure of social representations about hypertensive disorders in pregnancy evoked by 70 mothers

Referring to Figure 2, it is observed that the category death arises in the first quadrant, as the stronger representation of the HDPs, with a high frequency of evocation and low OME. In the second quadrant (intermediate nucleus), category 2 appears, the negative aspects of the disease, grouping the various feelings that permeate the experience of a high-risk pregnancy, especially with the HDPs. The category knowledge about the disease, also arose, in which complications and symptoms that were present in pregnancy were disclosed, especially changes which are the classic symptoms of HDPs: hypertension, epigastric pain, headache and edema. These signs and symptoms were justified by the women as abnormal situations in the gestational period, and that made them feel that something was happening that was outside of normality.

In quadrant 3, (the peripheral system) the fifth and third categories arose, called respectively, need for care and coping strategies. In this context, the women, realizing their clinical severity, felt the need for care to preserve her life and especially that of her child, and sought religiosity as a means to cope with the physical and emotional changes that the disease conferred. In a similar manner, the woman maintained perseverance in the fight against the disease supported the idea that, in preserving her own life, she played the maternal role of not depriving the premature child, also considered highrisk, of maternal care.

\section{Significance attributed to prematurity}

From the inducing stimulus «prematurity», $81 \%$ of evocations distributed in five categories (Figure 3) were obtained, where, in quadrant 1 , the word «death» was found as the strongest representation of prematurity.

Proceeding with the analysis of Figure 3, in the second quadrant the category fragility emerged the maternal expression of describing the premature infant as a "fragile baby." This term presented a high frequency of evocation and could be inserted as the central nucleus, if not for the high OME. The need for care category, in the third quadrant, revealed the maternal commitment in offering love and dedication to a premature baby, which denotes fragility and, therefore, necessitated special care.

\begin{tabular}{|c|c|c|c|c|}
\hline \multirow{4}{*}{$\begin{array}{l}\text { MOE }<2.5 \\
\text { Category 1-Death } \\
\text { Death }\end{array}$} & Frequency $(f)>67$ & \multirow[t]{2}{*}{ MOE $>2.5$} & \multicolumn{2}{|c|}{ Frequency $(\mathrm{f})>67$} \\
\hline & MOE & & $\mathrm{f}$ & MOE \\
\hline & 2.5 & Category 4 - Fragility & 98 & 3.0 \\
\hline & & Fragile baby & & \\
\hline \multirow[t]{8}{*}{ MOE $<2.5$} & Frequency (f) $<67$ & MOE $>2.5$ & \multicolumn{2}{|c|}{ Frequency (f) $<67$} \\
\hline & & & $f$ & MOE \\
\hline & & Category 2 - Need for Care & 65 & 3.1 \\
\hline & & Special care and love & & \\
\hline & & Category 3 - Negative aspects & 45 & 3.3 \\
\hline & & Grief, sadness, distress and guilt & & \\
\hline & & Category 5 - Coping strategies & 15 & 2.7 \\
\hline & & Struggle and faith & & \\
\hline
\end{tabular}

Figure 3 - Identification of the structure of social representations of prematurity evoked by 70 mothers 
In that same quadrant, negative feelings arose in the category negative aspects (distress, sadness and guilt) and reflected the maternal difficulties with the prematurity, initiated by guilt for not being able to carry the pregnancy to term and, after delivery, the vision of a sick baby surrounded by wires and appliances, which differed from the healthy child they desired. From the perspective of overcoming something contrary to expectations, women sought alternatives to live with and accept the new reality, and thus arose the category coping strategy, in which the words "faith" and "struggle" are highlighted as mechanisms for accepting a fact in the daily life that is contrary to the process of normal birth, and overcoming the adversities experienced with a premature child requiring intensive treatment.

\section{Significance attributed to the NICU}

For the inducing stimulus NICU, $89 \%$ of evocations obtained were of a similar nature. These words were grouped into three categories (Figure 4). The death category appears in the first quadrant, as the strongest representation of NICU. The understanding of the women about the ICU was revealed as a place in which children are very serious and close to death, and they understood it as frightening, where, often, one witnessed the death of other babies and the suffering of other mothers. This construction reinforced the feeling that to have one's child hospitalized in this environment was to live daily with the risk of losing him.

In the second quadrant, the category, significance of the NICU, gave rise to specialized care symbolized by technological devices, qualified professionals and special care. This specificity of care contributed to reframing this sector: though living daily with the meaning of death, this started to be replaced by the realization that the available resources increased the chances for survival of the child.

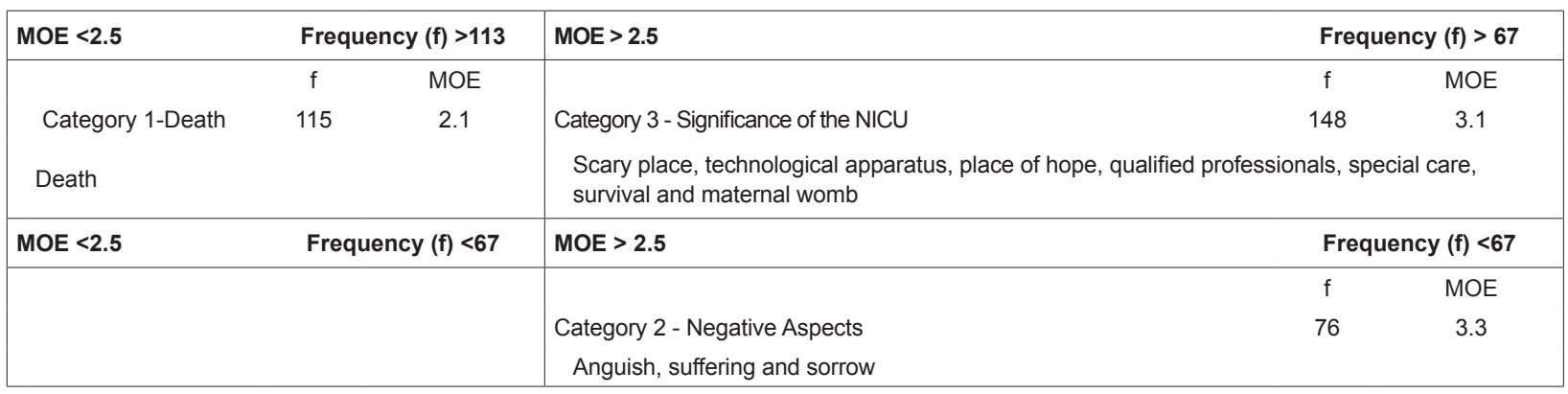

Figure 4 - Identification of the structure of social representations evoked by the NICU for the 70 mothers

With this comes a whole new significance for the NICU, as «maternal womb», giving it the sense of continuing the pregnancy and, therefore, being responsible for the completion of the pregnancy that was interrupted early. Thus, in the context of intensive care, the «technological devices» initially embodied a frightening objectification of the NICU and, later it is reframed as a place in which the child>s life is being safeguarded.

In the third quadrant, as the peripheral system, the category, negative aspects, is encountered, arising from the feelings of mothers as caregivers of the child in the
NICU. These difficulties were outlined when the mother, in the obstetric ward, listened to the pediatrician say that the child needed intensive care, and persisted during the first visit in the NICU and during the daily hospitalization of the child.

For better representation of this study, in Figure 5 the categories inherent to the three units analyzed are presented, which highlights the categories, death and negative aspects, common to all three themes discussed, followed by the categories of coping strategies and need for care, present in the universe of HDPs and prematurity. 


\begin{tabular}{|c|c|c|}
\hline \multicolumn{2}{|c|}{ Thematic units } \\
\hline Significance of HDPs & Significance of prematurity & Significance of the NICU \\
\hline Death & Death & Death \\
\hline Negative Aspects & Negative Aspects & Significance of the NICU \\
\hline Coping strategies & Coping strategies & \\
\hline Need for care & Need for care & \\
\hline Knowledge about the disease & Fragility & \\
\hline
\end{tabular}

Figure 5 - Categorization obtained about the representativeness of the hypertensive disorders of pregnancy, prematurity and the NICU for the 70 mothers

\section{Discussion}

In relation to this study, it was evident that social representations of mothers about the HDP sequence leading to premature birth, that progressed to the hospitalization of the child in the NICU, obtained the categories death and negative aspects presented as common to all three representative universes, by means of FWAT, confirming that this was an experience of a unique context, although with different consequences.

Initially, HDPs were associated to death, the women made real their own condition of vulnerability when faced with an unknown and surprising disease, that referred to the early hospitalization, family estrangement and powerlessness in the face of the impossibility of carrying the pregnancy to term. In this sense, death arose not only as the end of life, but as the opposite of the celebration of motherhood and the role played by women in the social context in which they lived: to carry a pregnancy to term and give birth to a healthy child.

For the interviewees, to live with the meaning of death, both for themselves and for the child, intensified anxieties and fears, the objectification of the real condition of the risks to which they were subjected. Death, by exterminating existence, introduces the contradiction, sadness and horror in one's heart ${ }^{(12)}$. Therefore, the perceived risk of death brought feelings with different intensities, such as fear, anxiety and guilt(13). Thus, women with HDPs experienced emotional changes that could harm them not only pathophysiologically, but also from the subjective aspect.

The categories need for care and coping strategies emerged as alternatives to avoid an unfavorable outcome of the disease and to remove the risk of imminent death. With this, upon hospitalization, women obtained specific treatment in search of their own survival and that of the child, relying on religiosity to cope with illness and the limitations it gave them, which represented an encouraging factor when facing a high risk pregnancy.
As a relevant part of life, religion cannot be neglected, and must be included as an addition to medicalized treatment ${ }^{(14-15)}$.

Premature birth represented the failure to carry the pregnancy to term and the uncertainties relating to the child's survival. It was the death of the idealized pregnancy that brought up insecurities and fears attributed to the experience of anticipatory grief(16). With the hospitalization of neonates in the NICU, the mothers forgot their own risks inherent in puerperal HDPs, directing their actions to their child. There was a kind of solicitude, dedication and restlessness adopted by them in order to contribute to the recovery of the child(17). Thus, preterm birth and hospitalization of the premature baby in the NICU could compromise the maternal and family emotional equilibrium(18).

It is known that the NICUs were created in order to provide conditions for the reduction of neonatal morbidity and mortality. However, it is clear that, in this environment, it is common for professionals to focus their actions toward the biological requirements of the newborn, whereas the fragmentation of maternal care and family needs occurs, which are also present in the context of the birth and hospitalization of a premature baby.

There is a tendency for the postpartum maternal risks to be less valued by the neonatal team as a result of the care that is being given to the newborn. However, it is essential to remember that the high-risk neonate often comes from high-risk pregnancies and that the postpartum women, due to complications to which they are still exposed, require special care involving the mother, the infant and the family.

Referring to the negative aspects intrinsic to maternal experiences with the HDPs and prematurity, there are perceptible social influences on motherhood carried by the woman that can cause disastrous repercussions on her emotional state, when something does not happen as expected. This fact puts women in a 
vulnerable family situation, especially for mothers who attributed to themselves the responsibility of having been affected by an illness that gave them the inability to produce a healthy child.

These social reflexes crystallize the negative aspects of HDPs with tendencies toward physical, emotional and social damage. As a function of this, it established the need for "caring" with special attention to the subjective aspects present in the experience of a high risk pregnancy and birth. Studies have demonstrated that the diagnosis of high-risk pregnancy was already a stressor and that anxiety and vulnerability of women to uncertainty of bringing the pregnancy to term were seen in those who experience gestational hypertension ${ }^{(8,19)}$.

In this circumstance, the results of this study indicated that women, faced with a pregnancy with a hypertensive disorder, and resulting in the birth of a premature child, experience losses, separations, conflicts and fears, which may influence the adverse effects of HDPs, premature delivery and subsequent hospitalization of a child in the NICU. In high-risk pregnancy, emotions and feelings of guilt flourish which may compromise the progression of the pregnancy ${ }^{(13)}$.

The perceived risk of death for both mother and child triggered the emotional aspects present in highrisk pregnancies, followed by premature birth and hospitalization of this child in the NICU. Accordingly, comprehensive care is required, based on maternal needs, offering support for coping with and adapting to this new reality. This finding is supported by other studies that show the need for health professionals to accommodate these mothers, so they feel more secure and valued ${ }^{(8,13)}$.

Overall, the consolidation of EVOC enabled us to identify that the word "death" arose with high frequency and was present in all three contexts analyzed. Thus, the category death was the central nucleus of the study of social representations of hypertensive disorders of pregnancy, which had consequences of preterm birth and hospitalization of the child in the NICU, for the 70 mothers studied.

Elements such as feelings, perceptions, significance, attitudes and difficulties arising from individualized expressions represented, collectively, the everyday interviews during the high risk pregnancy, labor, birth and postpartum. They composed: the category of negative aspects, present in all three situations analyzed; the categories, coping strategies and needs for care, evidenced in HDPs and prematurity; and knowledge about the disease, fragility and significance of the NICU, which represented specific facts of each situation investigated. These categories constituted the peripheral nucleus of the social representation of this study.

\section{Final Considerations}

Data analysis enabled the identification that, for the mothers in this study, the HDPs and their consequences, such as premature birth and hospitalization of the child in the NICU, revealed the construction of a negative social representation, which had death as its central nucleus, often with high evocation in the three contexts evaluated.

At first, the meaning of death was represented by the risk of maternal and fetal death. After delivery, the respondents appeared to forget their own risks and they projected them to those to which the children were exposed, resulting from prematurity and NICU hospitalization. In this scenario, even if the persistence of the high complexity service had decreased or removed the risk of maternal or fetal death, the meaning of death continued to be strong, due to the disruption of the idealized pregnancy and anticipation of the arrival of a child in a situation contrary to what was desired.

The lack of contrasting elements that composed the lower left quadrants, in the Figures regarding the situations investigated, indicated that no situation was opposed to common sense when it came to defining the central nucleus. This led us to suppose that few or almost no aspect of the care received by the women surveyed favored the social deconstruction of assigning a meaning of death to the HDPs and their consequences.

It is worth highlighting the relevance of this study for addressing the experience of women with hypertensive disorders of pregnancy, revealing situations that encompass the cycle of pregnancy and childbirth, the premature birth and hospitalization of the child in the NICU. Therefore, it is believed to be contributing to advances in the quality of nursing care and the dissemination of scientific knowledge on this little explored theme, with a view to ensuring decent care to women in situations of high risk pregnancy, so that they can cope with less injury from the adverse effects arising from a high risk pregnancy and birth.

\section{References}

1. Sibai B, Dekker G, Kupferminc M. Pre-eclampsia. Lancet. 2005;365:785-99.

2. Barton JR, Sibai BM. Prediction and prevention of recurrent preeclampsia. Obstetric and gynecology. 2008;112(2 pt 1):359-72. 
3. Khan KS, Wojdyla D, Say L, Gulmezoglu AM, Van Look PFA. WHO analysis of causes of maternal death: a systematic review. Lancet. 2006;367:1066-74.

4. Ministério da Saúde (BR). Secretaria de Atenção à Saúde. Departamento de Ações Programáticas Estratégicas: Manual dos comitês de mortalidade materna 3. ed. Brasília(DF): Ministério da Saúde, 2007. 5. Bakker R, Steegers EAP, Hofman A, Jaddoe VWV. Blood Pressure in Different Gestational Trimesters, Fetal Growth, and the Risk of Adverse Birth Outcomes The Generation R Study. Am J Epidemiol. 2011;174(7):797806.

6. Mendilcioglu I, Trak B, Uner M, Umit S, Kucukosmanoglu M. Recurrent preeclampsia and perinatal outcome: a study of women with recurrent preeclampsia compared with women with preeclampsia who remained normotensive during their prior pregnancies. Acta Obstet Gynecol Scand. 2004;83(11):1044-8.

7. Habli M, Levine RJ, Qian C, Sibai B. Neonatal outcomes in pregnancies with preeclampsia or gestational hypertension and in normotensive pregnancies that delivered at 35,36 , or 37 weeks of gestation. Am J Obstet Gynecol. 2007;197(4):406.e1-406.e7.

8. Souza NL, Araujo ACPF. Costa ICC. The meanings that postpartum women assign to gestational hypertension and premature birth. Rev Esc Enferm USP 2011;45(6):1285-92.

9. Sá CP. Núcleo central das representações sociais. 2aed. Petrópolis: Vozes; 2002.189p

10. Nóbrega SM, Coutinho MPL. O teste de associação livre de palavras In: Coutinho MPL, Lima AS, Oliveira FB, Fortunato $M L$,organizadores. Representações sociais. Uma abordagem interdisciplinar. João Pessoa: UFPB, Editora Universitária;2003 p. 67- 77.

11. Vergès P. L'évocation de I'argent: une méthode our la definition du noyau central d"une représentation. Bulletin de Psychologie. 1992;45(405):203-9.

12. Menossi MJ, Zorzo JCC, Lima RAG. The dialogic lifedeath in care delivery to adolescents with câncer. Rev. Latino-Am. Enfermagem fev 2012;20(1):126-34.

13. Carvalheira APP; Tonete VLP; Parada CMGL. Feelings and Perceptions of Women in the Pregnancy-Puerperal Cycle Who Survived Severe Maternal Morbidity. Rev. Latino-Am. Enfermagem nov/dez 2010;8(6):1187-94.

14. Faria JB, Seidl EMF. Religiosidade e enfrentamento em contexto de saúde e doença: revisão da literatura. Psicologia: Reflexão e Crítica. 2005;18(3):381-389.
15. Dourado V G, Pelloso S M. Gravidez de alto risco: o desejo e a programação de uma gestação. Acta Paul Enferm. 2007;20(1):12-7.

16. Maldonado MT. Psicossomática e obstetrícia. In: Mello Filho J, editor. Psicossomática hoje. Porto Alegre: Artes Médicas; 1992. p.208-14.

17. Silva IJ, Oliveira MFV, Silva SED, Polaro SHI, Radüz V, Santos EKA, Santana ME Care, self-care and caring for yourself: a paradigmatic understanding thought for nursing care.Rev Esc Enferm USP. 2009;43(3):697-703. 18. Correia LL, Carvalho AEV, Linhares MBM. Verbal contents expressed by mothers of preterm infants with clinical emotional symptoms. Rev. Latino-Am. Enfermagem. jan/fev 2008;16(1):64-70.

19. Black KD. Stresss, symptoms, self-monitoring confidence, well-being, and social support in the progression of preeclampsia/gestacional hypertension. J Obstet Gynecol Neonatal Nursing. 2007;36:419-29. 